\title{
The effect of processing parameters on the mechanical properties of kenaf fibre plastic composite.
}

\begin{abstract}
This paper investigates the effects that processing parameters, including temperature and speed, have on the mechanical properties of kenaf fibre plastic composite. Kenaf fibre was used to fabricate a composite material along with polypropylene (PP) as a binding material. The composite was manufactured using a newly developed compression moulding machine. Tensile and impact tests were performed on the PP/kenaf composite to characterise its mechanical properties. The tensile properties of PP/kenaf composite increased by $10 \%$ after the addition of unidirectional kenaf fibre (UKF). However, its impact properties simultaneously deteriorated. Dynamic mechanical analysis (DMA) was carried out to examine the material properties. Results show that the storage modulus $\left(\mathrm{E}^{\prime}\right)$ and loss modulus $\left(\mathrm{E}^{\prime \prime}\right)$ increase with the addition of UKF. However, its addition decreases the tan $\delta$ amplitude. The fracture surface of PP/kenaf composite was investigated by SEM. The newly invented compression moulding machine illustrates a new trend in processing parameters of long kenaf fibre plastic composite.
\end{abstract}

Keyword: Binding materials; Fracture surfaces; Impact property; Long kenaf fibres; Moulding machines; Plastic composites; Storage moduli. 